\title{
Musical Engagement and Parent-Child Attachment in Families with Young Children During the Covid-19 Pandemic
}

\author{
Selena Steinberg ${ }^{1 *}$, Talia Liu ${ }^{1,2}$, Miriam D. Lense ${ }^{1,2^{*}}$ \\ ${ }^{1}$ Vanderbilt University, Nashville, TN, USA \\ ${ }^{2}$ Vanderbilt University Medical Center, Nashville, TN, USA \\ *Correspondence: \\ Selena Steinberg or Miriam D. Lense \\ selena.k.steinberg@vanderbilt.edu \\ miriam.lense@vanderbilt.edu
}

Keywords: music, parent-child attachment, parent-child interactions, Covid-19, early childhood

\begin{abstract}
The onset of the Covid-19 pandemic has disrupted the lives of families in the United States and across the world, impacting parent mental health and stress, and in turn, the parentchild relationship. Music is a common parent-child activity and has been found to positively impact relationships, but little is known about music's role in parent-child interactions during a pandemic. The current study utilized an online questionnaire to assess the use of music in the home of young children and their parents in the USA and Canada during Covid-19 and its relationship with parents' affective attachment with their child. Musical activity was high for both parents and children. Parents reported using music for both emotion regulation and to socially connect with their children. Parent-child musical engagement was associated with parent-child attachment, controlling for relevant parent variables including parent distress, efficacy, education and parent-child engagement in non-musical activities. These results indicate that music may be an effective tool for building and maintaining parent-child relationships during a period of uncertainty and change.
\end{abstract}

\section{Introduction}

"During times of sadness or stress we listen to favorite songs, dance, and this relieves stress and lifts moods" - parent of a 67 month old

"My youngest son pretty much lives through music, and it seems to be more acute now than before the lockdown." - parent of a 33 month old

The unprecedented Covid-19 global pandemic has impacted families' daily lives across the world. A record number of Americans filed for unemployment in light of the pandemic, with the unemployment rate rising from 3.5\% in February 2020 to 14.7\% in April 2020, a rate higher than it had been in 80 years (Altig et al., 2020). In particular, the pandemic has been associated with an increase in risk factors for many mental health conditions as a result of social distancing regulations and state-wide stay-at-home orders. According to a Center for Disease Control report 
from August 2020, 40.9\% of over 5,000 US adults reported at least one adverse mental or behavioral health condition (Czeisler et al., 2020). Compared to reported symptoms in 2019, the prevalence of symptoms of anxiety disorder more than tripled and the prevalence of depressive disorder nearly quadrupled (Czeisler et al., 2020).

In addition to the impact of the Covid-19 pandemic on the stress levels and mental health of individuals, the pandemic rapidly altered family life. Many schools and child care centers (e.g., daycares) closed and parent caregivers lost wages and jobs or had to work remotely (Bartik et al., 2020; U.S. Chamber of Commerce Foundation, 2020). Caregivers had to care for and entertain their children and simultaneously support their families financially and keep them safe. Working mothers of children under five years old reported increased difficulty balancing work and family during Covid-19 (Del Boca et al., 2020). During the pandemic, parents spent more time with their children in different types of activities, including playing more games, watching more television, and playing with more toys (Lee et al., 2020). Because of the added stressors of parenting during a pandemic, caregivers of children were at an increased risk of experiencing adverse mental health symptoms compared to non-parents (Russell et al., 2020). Parents' reports of daily mood were significantly more negative during the pandemic than before its onset (Gassman-Pines et al., 2020). Furthermore, the additional parenting needs and increased stressors were contributors to compromised parent-child relationships (Russell et al., 2020). In a national survey study assessing the physical and emotional well-being of parents and children in the United States in June 2020, there were significant links between parents' mental health, children's stress, and parent-child closeness and conflict (Russell et al., 2020). Parents who greatly increased time spent with their child due to the pandemic experienced higher levels of stress, anxiety, and frustration towards their child (Calarco et al., 2020). In light of Covid-19's impact on family life, it is important to consider activities that parents' may use to regulate their mental health/emotional state and their connection with their children.

Music can positively impact mental health in both clinical and non-clinical populations. Group singing can serve as a coping mechanism for people experiencing adverse situations (Von Lob et al., 2010). Music therapy may be an effective treatment for depression (Erkkilä et al., 2011; Hanser \& Thompson, 1994) and anxiety (Bulfone et al., 2009) in a variety of populations. Regarding parents specifically, after participating in a ten-week group music therapy program, parents facing disadvantages or with a child with a disability reported improvements in their mental health and decreased levels of irritability (Nicholson et al., 2008). Participation in a group parent-infant music program was associated with faster improvements in mothers' postnatal depressive symptoms versus participation in a non-music play group or usual care (Fancourt \& Perkins, 2018a; Perkins et al., 2018).

Furthermore, everyday musical experiences aid in emotion regulation (Thayer et al., 1994) and stress reduction (Yehuda, 2011). In everyday situations, people select what music to listen to based upon their current emotional situation; in other words, listeners seek out music that can control, support, or change their emotional state (Thoma et al., 2012). Listening to music is associated with lower subjective stress levels (Linnemann et al., 2015) and with lower levels of cortisol (Kreutz et al., 2012). In particular, maternal singing to babies and infants has been found to modulate parents' and infants' arousal levels (Cirelli et al., 2020). Additionally, mothers smile more when singing than speaking to their infant (Trehub et al., 2016) and report higher positive affect following singing with their infant as compared to non-musical play (Fancourt \& Perkins, 2018b). In a survey of over 2,000 parents with children under three years of age, parents 
who sang or played music daily reported fewer depressive symptoms than those that did not (Custodero et al., 2003).

Music also supports connectedness to others and social bonding (Dunbar, 2012; Freeman, 2000). Parents frequently report using music with their baby as a way to encourage interaction and connectedness (Custodero \& Johnson-Green, 2008). The mother-baby bond was significantly stronger for mothers who were encouraged to sing to their babies compared to mothers that were not (Persico et al., 2017). Parents participating in shared parent-child musical experiences report increased closeness to their child compared to those participating in nonmusical play (Fancourt \& Perkins, 2018b). Even during early childhood, joint musical experiences are associated with children's prosocial behavior toward other children or adults (Cirelli et al., 2014; Cirelli et al., 2018; Kirschner \& Tomasello, 2010).

Several particular elements of music may support its relationship to social bonding. Tarr et al. (2014) suggest that two mechanisms that support the relationship between music and social bonding are interpersonal synchronization and the release of endorphins. Music has a predictable, rhythmic structure that facilitates interpersonal movement synchrony with others (Savage et al., 2020). The pitch range and scale structure of children's music may also allow for coordinating vocal interactions, supporting group experiences and connectedness (Savage et al., 2020). Additionally, the repetitive structure and multimodal social cues (voice, facial expressions, movement, touch) employed during musical games sustain children's attention and support their social learning particularly when in the meaningful context of parent-child interactions (Lense \& Jones, 2016; Mehr et al., 2016; Trehub et al., 2016).

Musical experiences are natural and common in early childhood interactions (Politmou et al., 2018). Several studies focused on characterizing the musical experiences of infants reported frequent musical activity and exposure (e.g. Custodero, et al., 2003; Mendoza \& Fausey, 2019). Studies of preschool children are rarer and have mixed results, with some reporting the use of music daily (Blackburn, 2017) and others reporting less frequent use (de Vries, 2009). The types of musical activities in early childhood are also varied (Steinberg, Shivers, et al., 2020). Several studies note that singing is a frequent parent-child musical activity (Blackburn, 2017; Ilari, 2005; Mendoza \& Fausey, 2019). However, other common children's musical activities include the use of musical toys (Mendoza \& Fausey, 2019), playing recorded music (de Vries, 2009; Mendoza \& Fausey, 2019), and listening and dancing to music with others (Blackburn, 2017). Different music activities can have different purposes. For instance, parents may use passive musical activities, like listening to music or watching music videos, to keep their child occupied, while active, joint parent-child music activities, like singing or dancing, may be used as a social experience (Lense et al., 2020; Steinberg, Shivers et al., 2020).

Given the positive social and emotional effects of musical engagement, along with the prevalence of music use in the home of parents and their young children, it is important to understand the role of everyday musical experiences during the Covid-19 pandemic for parents, their young children, and the parent-child relationship. In the present study, we describe the ways in which parents and their children engage with music during a global pandemic and evaluate if parent musical engagement, child musical engagement, or joint parent-child musical engagement changed as compared to before the Covid-19 pandemic. We then explore the purposes of music use during Covid-19 with an emphasis on the use of music for emotion regulation and social connection. Finally, we consider if parent-child music engagement during Covid-19 relates to the parent-child relationship; specifically, we examine if parent-child music engagement is 
associated with parents' affective attachment to their child, i.e., the emotions and thoughts parents have about their child and the parent-child relationship.

\section{Materials and Method}

\section{Participants}

Participants were 177 caregivers of children between six and seventy months old $(\mathrm{M}=$ $35.9, \mathrm{SD}=17.4)$, with all ages well-represented throughout the age range. Children were approximately evenly split by gender $(48.0 \%$ male) and by whether they had a sibling $(48.6 \%$ only child). Respondents of the survey were primarily the children's biological mothers $(94.4 \%)$ and were highly educated (61.7\% with a graduate degree). Participants primarily lived in the United States (74\%) and Canada (24\%). During the Covid-19 pandemic, participants reported losing child care outside of the home, reducing time spent outside of the home, and spending much more time with their children. Full demographics and impact of Covid-19 on caregivers can be found in Table 1 .

\section{Table 1}

Sample (n=177) Demographics and Covid-19 Impact

Child

\begin{tabular}{ll}
\hline Sex (\% male) & 48.0 \\
Age in months (mean (SD)) & $35.9(17.4)$ \\
Only child (\%) & 48.6 \\
Respondent & \\
\hline Relation to child (\%) & 94.4 \\
Biological mother & \\
Education level (\%) & 9.7 \\
Less than bachelor's & 28.6 \\
Bachelor's degree & 61.7 \\
Graduate degree & \\
Prior to Covid-19 (\%) & 78.5 \\
Worked outside home & 75.7 \\
Childcare outside home & \\
During Covid-19 & 18.1 \\
Worked outside home (\%) & 8.5 \\
Childcare outside home (\%) & 7.3 \\
Reduced or lost wages (\%) & 10.2 \\
Worked reduced hours (\%) & 61.6 \\
Did not leave home (\%) & 83.6 \\
Did not visit friends (\%) & 1.7 \\
Received a positive Covid-19 test (\%) & \\
Time spent with child (\%) & 54.2 \\
Much more & 17.0 \\
Somewhat more & 20.9 \\
About the same & 4.5 \\
Somewhat less &
\end{tabular}


Much less

Parent distress (K6)

Mean (SD)

Moderate distress (\%)

Severe distress (\%)

Parenting self-efficacy (mean (SD))

Parent-child attachment (mean (SD))
3.4

$6.7(4.3)$

45.8

9.6

$4.2(0.7)$

$76.3(8.3)$

\section{Procedure}

Data were collected via an online survey using REDCap, a secure, online data server (Harris et al., 2009). The survey assessed demographic information (including impact of Covid19 on the family), parent and child music engagement and activities, and parent-child attachment, as well as other relevant parent/family characteristics known to impact parent-child attachment such as parent mental health and parenting efficacy. All measures are described below. The survey was available from April to August 2020 and took approximately 20 to 30 minutes to complete. Over $90 \%$ of participants filled out the survey in April or May of 2020 (during the first two to three months of lockdown and school/daycare closings in the USA and Canada). The study was approved by the university IRB. Participants provided informed consent prior to accessing the questionnaire.

\section{Measures}

\section{Musical Engagement}

Parent-Child Musical Engagement. Participants responded to an adapted version of the standardized Music@Home scale (Politimou et al., 2018). The measure consisted of 17 items that assessed respondents' use of music with their child in the home. Participants used a Likert scale ranging from one (completely disagree) to seven (completely agree) to indicate their agreement with statements like "I sing to/with my child several times (e.g. 5-10) a day." Items were summed for a total Music@Home score, ranging from 17 to 119 (Cronbach’s alpha = 0.92). Items were also divided into two subscales, Child Active Engagement with Music ( 9 items; Cronbach's alpha $=0.89$ ) and Parent Initiation of Musical Activities (8 items; Cronbach's alpha $=0.92$ ).

Child Musical Engagement. Participants used a Likert scale ranging from zero (zero minutes) to six (more than two hours) to indicate the average amount of time their child spent in various music activities each day. Items included singing, playing instruments, listening to recorded music, playing with musical toys, watching music videos on a TV/tablet, dancing to music, and engaging in music activities with another person.

Participants used a five-point Likert scale ranging from "much less" to "much more" to indicate how much time their child spent watching music videos, listening to recorded music, and engaging in music with another person during Covid-19 as compared to before the pandemic.

Participants used a Likert scale ranging from one (completely disagree) to seven (completely agree) to indicate their agreement with reasons that they or a family member use music in the home with their child. There were 10 possible reasons such as to soothe the child when upset, to get their child's attention, as part of night-time routines, and to practice 
communication skills. Responses were re-coded into agree or disagree and then summed for the number of items endorsed to represent a total Function of Music Activities score (Cronbach's alpha $=0.75)$.

Parent Musical Engagement. Participants used a five-point Likert scale ranging from "much less" to "much more" to indicate how much time they spent listening to and making music during Covid-19 as compared to before the pandemic. Participants also answered Likert scale questions, ranging from one (completely disagree) to seven (completely agree), about how listening to and making music helps them to regulate their emotions, regulate their children's emotions, socially connect with adults in and outside of their family, and socially connect with their children. Finally, participants indicated how much they now use music to help with their emotion regulation and social connection compared to an average day before Covid-19 using a five-point Likert scale ranging from "much less" to "much more".

\section{Parent-Child Attachment}

Parent-child attachment was measured using the Postnatal Attachment Questionnaire (PAQ; Condon \& Corkindale, 1998). The PAQ consists of 19 Likert scale items that assess parents' affective attachment to their child, using questions like "when I am with the child I feel tense and anxious." Items were summed for a total Parent-Child Attachment score (Cronbach's alpha $=0.78$ ). The PAQ was originally intended for use with infants but has also been used to assess parent-child attachment in older children (e.g., Goodman \& Glenwick, 2012; Steinberg, Shivers et al., 2020) because it emphasizes parents' feelings towards their child, rather than children's feelings or behaviors towards the parent. We changed the word "baby" to the word "child" in order to make the survey more applicable to our sample.

\section{Parent Distress}

Parent distress was measured using the Kessler Screening Scale for Psychological Distress (K6; Kessler et al., 2002). The K6 consists of six Likert scale items, ranging from zero (none of the time) to four (all of the time), that assess parents' mental health through capturing the reported frequency of feelings like nervousness, hopelessness, sadness, and restlessness. Items were summed for a total Parent Distress score (Cronbach's alpha $=0.83$ ), ranging from zero to 24. A score of zero indicates no distress, one to five indicates low distress, six to 12 indicates moderate distress, and 13-24 indicates high distress (Forman-Hoffman et al., 2014; Tomitaka et al., 2019). Parent distress scores and categorizations for the current sample are provided in Table 1.

\section{Parenting Self-Efficacy}

Parenting self-efficacy was measured using one question: "Which of the following statements best describes how you feel about yourself as a parent?". Participants responded using a Likert scale ranging from one (not very good at being a parent) to five (a very good parent). This item was adapted from the Longitudinal Study of Australian Children (Zubrick et al., 2008).

\section{Non-Musical Parent-Child Activities}

To measure overall time spent in parent-child activities, participants responded to the Family Activities Questionnaire (FAQ), adapted from questions used in the Millennium Cohort Study (Hansen et al., 2010). Parents responded to Likert scales ranging from one (hardly ever) to 
five (several times a day) to describe how frequently they engaged in five different activities with their child (e.g., reading, drawing, playing outdoor games). Items were summed to indicate a total Parent-Child Activity score (Cronbach's alpha $=0.59$ ).

\section{Data Analysis}

Descriptive statistics were examined for relevant music variables, capturing parent-child musical engagement, child music activities, and parent musical engagement during the Covid-19 pandemic. All five-point Likert items to assess change in music activities during versus preCovid-19 were scaled to range from -2 (much less) to +2 (much more), so that a score of zero reflected a response of "about the same". We used $t$-tests (one sample, two-tailed) to assess whether parents' perceptions of music activities/reasons for using music during Covid-19 were significantly different than before Covid-19. Correlations were calculated between parent-child musical engagement, parent-child attachment, parenting efficacy, parent distress, non-musical family activities, parent education, child age, and change in time spent with child during Covid19. Additionally, we conducted exploratory analyses investigating correlations between particular musical activities, parent reasons for using music with their child, and parent-child attachment. ${ }^{1} \mathrm{~A}$ linear regression model was used to examine the relationship between parentchild musical engagement and parent-child attachment, controlling for relevant parent variables, change in time parent spent with child due to Covid-19, and child age. Due to the large number of analyses conducted, only $p$-values of $<0.01$ are reported as significant. All analyses were run in SAS University Edition version 9.4.

\section{Results}

\section{Musical Experiences}

\section{Parent-Child Musical Engagement}

Parent-child musical engagement during Covid-19 (based on Music@Home total scores)was high across the sample though there was also substantial individual variability in music engagement. Total and subscale scores can be found in Table 2. [insert table 2 near here]

\section{Table 2}

Parent-child music engagement and child music activities.

\begin{tabular}{|c|c|c|c|}
\hline & Mean & SD & Range \\
\hline \multicolumn{4}{|l|}{ Music@Home } \\
\hline Total Score & 96.6 & 14.8 & $60-119$ \\
\hline Child Active Engagement & 54.0 & 7.70 & $28-63$ \\
\hline Parent Initiation of Music Activities & 42.6 & 9.12 & $14-56$ \\
\hline \multicolumn{4}{|c|}{ Child Music Activities } \\
\hline Singing & 2.9 & 1.7 & $0-6$ \\
\hline Playing instruments & 2.4 & 1.4 & $0-6$ \\
\hline Listening to music & 3.6 & 1.6 & $0-6$ \\
\hline Musical toys & 2.2 & 1.5 & $0-6$ \\
\hline Watching musical videos & 3.0 & 1.7 & $0-6$ \\
\hline Dancing to music & 2.8 & 1.6 & $0-6$ \\
\hline
\end{tabular}

\footnotetext{
${ }^{1}$ We thank our reviewers for this suggestion.
} 


$\begin{array}{rlll}\text { Engaging in music socially } & 3.1 & 1.5 & 0-6 \\ \text { Function of Music Activities } & 7.2 & 2.5 & 0-10\end{array}$

Note. Possible ranges: Music@Home Total Score: 17-119; Child Active Engagement: 9-63; Parent Initiation of Musical Activities: 8-56; Child Music Activities: 0-6; Function of Music Activities: 0-10.

\section{Child Musical Engagement}

Parents reported that their child participated in a variety of musical activities (Table 2). Children spent the most time (between 20 and 59 minutes a day) listening to music, engaging in music with another person, and watching music videos. Compared to an average day before Covid-19, parents reported that their child spent significantly more time watching music videos, $t(173)=14.10, p<0.0001, d=1.07$, listening to recorded music, $t(173)=9.37, p<0.0001, d=$ 0.71 , and engaging in music with another person, $t(173)=8.74, p<0.0001, d=0.66$.

Parents endorsed on average between seven to eight (out of ten) reasons for using music with their child. The most popular reason for using music was to keep busy or pass the time while waiting ( $88.7 \%$ endorsed), while the least commonly endorsed reason was to help with transitions between activities (55.9\% endorsed). The percent of parents that endorsed each reason can be found in Table 3 .

\section{Table 3}

Percent of parents that endorsed using music with their child for each reason

Keep busy/pass the time while waiting

Interact with child in social games

Practice academic skills

Soothe child when upset

As part of other routines

Distract child

As part of nighttime routine

Practice communication skills

Get child's attention

Help with transitions between activities
Percent

88.7

83.1

77.4

76.8

71.8

71.2

70.6

66.7

58.8

55.9

There were small, significant correlations between various child music activities and reasons that parents used music with their children (controlling for child's age). Activities that involved children's active participation such as playing instruments, playing with musical toys, dancing to music, and engaging in music socially were generally the most commonly and most strongly correlated with specific functions of musical activities. In contrast, the activity of watching music videos was only associated with the reasons of practicing academic skills, practicing communication skills, and distracting the child. The full correlation table can be found in Table 1S in the supplement.

\section{Parent Musical Engagement}


In regard to their own music engagement, parents reported listening to, $t(176)=7.47, p<$ $0.0001, d=0.56$, and making, $t(176)=2.76, p<0.01, d=0.21$, music during Covid-19 significantly more than before the pandemic. Parents agreed or strongly agreed that listening to and making music helps to regulate their emotions, regulate their child's emotions, and helps them to socially connect with their children (Table 4). They also reported that they were using music for these purposes significantly more during Covid-19 than before the pandemic, $p$ 's $<$ $0.0001, d$ 's $=0.51$ (regulate own emotions), 0.94 (regulate child's emotions), 0.99 (socially connect with child). In comparison, compared to before the pandemic, during Covid-19 parents were less likely to use music to socially connect with other adults not in their family, $p<0.001$, $d=-0.28$. There were no changes in using music to connect with adults in their family during the pandemic.

\section{Table 4}

Parent reports of the purpose of listening to or making music during Covid-19.

\begin{tabular}{lllll} 
& \multicolumn{3}{l}{ Agreement $^{\mathrm{a}}$} & \multicolumn{3}{l}{${\text { Covid-19 } \text { Change }^{\mathrm{b}}}$} \\
& & & & \\
& M & SD & M & SD \\
Regulate my emotions/change mood or physical state & 5.78 & 1.05 & $0.43^{* * *}$ & 0.84 \\
Regulate my child's emotions & 5.66 & 0.97 & $0.64 * * *$ & 0.68 \\
Socially connect with other adults not in my family & 4.49 & 1.29 & $-0.30^{* *}$ & 1.07 \\
Socially connect with other adults in my family & 4.90 & 1.26 & 0.16 & 0.90 \\
Socially connect with my child/children & 5.82 & 0.89 & $0.79 * * *$ & 0.80
\end{tabular}

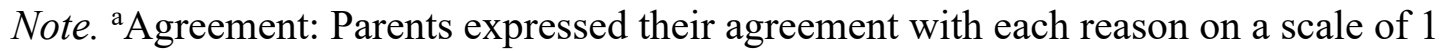
(completely disagree) to 7 (completely agree). ${ }^{b}$ Covid-19 Change: Parents expressed how much they currently used music for each reason compared to an average day before Covid-19 where -2 $=$ much less, $-1=$ somewhat less, $0=$ about the same, $1=$ somewhat more, and $2=$ much more. ** $p<0.001 * * * p<0.0001$

\section{Correlations between Parent-Child Attachment and Other Variables}

There was a significant, small, positive correlation between parent-child musical engagement and parent-child attachment, $r=0.29, p<0.001$. Parent-child attachment was also significantly correlated with parent distress, $r=-0.40, p<0.001$, parenting self-efficacy, $r=$ $0.50, p<0.001$, and parent education, $r=-0.27, p<0.001$. Parent-child musical engagement was significantly correlated with non-musical family activities, $r=0.23, p<0.01$. The full correlation matrix can be found in Table 5 .

\section{Table 5}

Correlations between parent-child attachment, parent-child musical engagement, and other variables
1.
2. 3.
4.
5.
6.
7.
1. Attachment
2.Music@Home
$0.29^{* * *}$
3. Parent distress
$-0.40^{* * *}-0.11$
4. Parenting self-efficacy
$0.50^{* * *}$
$0.10-0.32^{* * *}$ 
5. Parent education $\quad-0.27^{* *} \quad-0.05 \quad 0.04 \quad 0.02$

6. Child age $\quad-0.16 \quad-0.11 \quad-0.16 \quad-0.07 \quad 0.11$

7. Non-musical family $\quad 0.16 \quad 0.23^{*}-0.18 \quad 0.10 \quad 0.14 \quad 0.16$ activities

$\begin{array}{llllllll}\text { 8. Time spent with child } & -0.14 & 0.11 & -0.09 & 0.02 & 0.29^{* * *} & 0.19 & 0.17\end{array}$ during Covid-19

${ }^{*} p<0.01 * * p<0.001 * * * p<0.0001$

\section{Parent-Child Attachment and Parent-Child Musical Engagement}

The model including Music@Home total score, parent distress and self-efficacy, parent education level, child age, non-musical family activities, and change in time spent with child during Covid-19 significantly related to parent-child attachment scores, $F(7,165)=18.61, p<$ 0.0001 . While the largest predictors of parent-child attachment were parent-related variables of parent distress, self-efficacy, and parent education, parent-child music engagement was still significantly associated with parent-child attachment even when controlling for these variables. In contrast, non-musical family activities was not a significant predictor.

Table 6

Parent-child attachment model

$\begin{array}{llll} & \beta & t & \eta_{\mathrm{p}}{ }^{2} \\ \text { Intercept } & 62.04 & 10.10^{* * *} & \\ \text { Music@Home total score } & 0.10 & 2.97^{*} & 0.051 \\ \text { Parent distress } & -0.50 & -4.15^{* * *} & 0.094 \\ \text { Parenting self-efficacy } & 4.21 & 5.98^{* * *} & 0.178 \\ \text { Parent education } & -1.51 & -3.69 * * & 0.076 \\ \text { Child age } & -0.06 & -2.08 & 0.025 \\ \text { Non-musical family activities } & 0.27 & 1.57 & 0.015 \\ \text { Time spent with child during Covid-19 } & -0.77 & -1.67 & 0.017 \\ & & & \\ \mathrm{R}^{2}=0.44 & & & \\ & & & \end{array}$

To further unpack how specific music activities relate to parent-child attachment, we also conducted exploratory correlations between parent-child attachment and the two Music@Home subscales, as well as between parent-child attachment, specific child music activities, and specific reasons why parents used music with their child (controlling for other variables significantly associated with attachment and child age). There were significant small-tomoderate correlations with several items, notably the Music@Home Parent Initiation of Music subscale $(r=0.26, p<0.001)$, three of the child music behavior items (playing instruments, $r=$ $0.31, p<0.001$; dancing to music, $r=0.29, p<0.001$; engaging in music socially, $r=0.29, p<$ 0.001 ), and several of the reasons for using music. See Table $2 \mathrm{~S}$ in the Supplement for all correlations. 


\section{Discussion}

The Covid-19 pandemic considerably altered the lives of parents of young children. Disruptions to everyday life, including loss of childcare (Patrick et al., 2020) and changes in employment situations (Craig \& Churchill, 2020) were common across the world as a result of mandated lockdowns and stay at home orders, with parents of young children experiencing increased stress levels and time spent with their children (Calarco et al., 2020; Russell et al., 2020). Given the high prevalence of parent-child musical engagement in the home (Politmou et al., 2018) and the known benefits of music for emotion regulation and social connection (Dunbar, 2012; Freeman, 2000; Moore, 2013), the current study aimed to understand how parents and children engaged in music activities during the pandemic. Results demonstrated that 1) parents frequently engaged in musical activities with their young children during the Covid-19 pandemic; 2) parents perceived that their own and their child's music activities increased during Covid-19; 3) parents reported using music for both their own and their child's emotion regulation, as well as for social connection with their children during Covid-19; and 4) parentchild music engagement significantly predicted parent-child attachment, controlling for relevant parent variables, including parent distress, efficacy, and education, parent-child engagement in non-musical activities, child age, and change in time spent with their child during Covid-19.

Parents frequently engaged in musical activities with their child during the Covid-19 pandemic. Even though life and routines drastically changed for families during the pandemic, parent-child music activities remained a part of parent-child interactions consistent with the ubiquity of parent-child musical engagement during non-pandemic times (Steinberg, Shivers et al., 2020). In fact, parents reported that their child's, their own, and their joint engagement with music increased overall during the pandemic; effect sizes for these perceptions of changes in music activities were medium to large. Parents perceived that their child listened to music, watched music videos, and engaged in music with another person significantly more than they did before the pandemic. Listening to music and watching music videos (passive musical activities) and engaging in music socially (an active, shared musical activity) were the activities that parents reported children spent the most time doing, perhaps reflecting both parents' need to keep children busy alone while parents attended to other matters and their increased time with their child. Indeed, parents reported using music for specific functional purposes with their child, which aligned with the specific types of musical activities. These findings are similar to those of other music questionnaire studies, which suggested that listening, singing and dancing to music with others are common activities for children under five years of age (Blackburn, 2017; Custodero et al., 2003); families appear to continue to utilize these activities, perhaps at an increased level, during Covid-19.

There was a strong consensus (means that fell between agree and strongly agree) that parents listened to and/or made music for their own and their children's emotion regulation and in order to socially connect with their children. Indeed, effect sizes were strong for parents using music as a tool for/with their children's emotional and social needs versus parents using music to connect with other adults (within or outside of their household). This may reflect the increased time parents were spending with their child due to Covid-19, the importance of parents in supporting children's social-emotional needs, and/or the general centrality of the parent-child relationship for parents of young children (Borkowski et al., 2001). Music has been linked to several positive psychosocial outcomes in regard to emotions, relationships, and mood including for parents of young children (Croom, 2015; Custodero et al., 2003; Fancourt \& Perkins, 2017; 
Hargreaves \& North, 1999). Our results indicate that during a global pandemic, music continues to serve as a social and emotional tool for parents and children.

Consistent with this, parent-child musical engagement was positively related to parentchild attachment, even when controlling for high parent distress levels during Covid-19 and parenting efficacy and education, constructs that are highly related to parent-child attachment (Atkinson et al., 2000; Kohlhoff \& Barnett, 2013). In contrast, spending time with children in non-musical activities did not significantly relate to parent-child attachment. When examining the two Music@Home subscales separately, the Parent Initiation of Music subscale was particularly associated with parent-child attachment. This may reflect the importance of parents being actively engaged in an activity with their child and/or their intentionality in sharing meaningful, social experiences with their child (note that the Postnatal Attachment Questionnaire used in the present study reflects parents' affective attachment to their child). Consistent with this, exploratory analyses revealed that the music activities most associated with parent-child attachment were ones which afforded opportunities for parents and children to have productive, active roles in a social context such as dancing or engaging in social games. The relationship between interpersonal, social music activities with parents' affective attachment is also consistent with broader theories of musicality emerging because it supports social bonding (Savage et al., 2020).

Although not causal, the positive relationship between parent-child musical activities and parent-child attachment suggests that joint musical experiences may be a contributor to facilitating parents' affective connection to their child even during the increased stress, increased parenting time, and other life changes occurring in the midst of a global pandemic. Due to the cross-sectionality of the current study, the direction of the findings cannot be tested, and it may be that parents who are close to their children engage in more musical activities (though note no relationship was observed between parent-child attachment and non-musical activities). Of course, other family, child, and parent factors and activities which were not captured in the current study also contribute to parent-child attachment during Covid-19.

As parent and child stress, mental health difficulties, and parent-child conflict are increased during Covid-19 (Russell et al., 2020), it is essential to consider activities that support parent-child attachment, which is linked with both parent and child well-being (de Cock et al., 2016; Johnson, 2013). Previous research with parents of children under twelve years old found that activities like playing games and watching TV with their child increased the most during the Covid-19 pandemic, with less than half $(40.1 \%)$ of their participants reporting an increase in parent-child singing (Lee et al., 2020). As the current study indicates that music in particular is beneficial for supporting the parent-child relationship, future work can consider how to support parents in incorporating musical activities into their home routines during times of increased caregiving responsibilities and stress.

Another limitation of the current study to be addressed in future studies was the high education level of participants $(61.7 \%$ with a graduate degree), which may have contributed to parent reports of frequent musical activities (e.g. Custodero et al., 2003). While we controlled for parent education in the parent-child attachment model, a more representative sample could expand our knowledge of music in the home across diverse families and situations. At the onset of Covid-19, highly educated professionals had the most flexibility to work remotely from home (Dey et al., 2020). Likewise, our participants exhibited this flexibility: $78.5 \%$ of participants worked outside the home before the pandemic, while $18.1 \%$ worked outside the home during the pandemic, with only $7.3 \%$ of participants reporting reduced or lost wages. Thus, while music and 
parent-child attachment were related for this group of parents, the relationship may differ for parents experiencing more adverse direct effects of Covid-19, like losing employment. At the same time, our sample did exhibit elevated levels of parent distress, with $45.8 \%$ of parents experiencing moderate levels of distress and $9.6 \%$ of parents experiencing severe levels of distress. Comparatively, in 2018 , only $21.4 \%$ of a national sample of adults with children under eighteen years old in their home exhibited moderate or severe levels of parent distress (Twenge \& Joiner, 2020). Given the use of an online survey to collect data, parents with internet access and time to complete the survey were the most likely to fill it out. As such, the sample may have spent more time with their children during the pandemic than the general parent population, and had more time to engage in musical (and other) activities. Additionally, the majority of the present data was collected in the first months of the pandemic-associated closures and lockdowns in the USA and Canada. Longitudinal studies could assess how use of music and its impact on the parent-child relationship changes with prolonged experience of the pandemic. Finally, for a subset of items, participants were asked to retrospectively compare their purposes for using music before the pandemic to their current situation, which may be subject to response bias.

Music is a powerful tool for bringing parents and their children together. Amidst changed routines and high stress of the Covid-19 pandemic, music was a tool for emotion regulation and a way for parents to socially connect with their children; parents' scores on the standardized Music@Home survey significantly related to their affective attachment towards their child. Findings suggest that even during times of increased caregiving needs and high parent distress, music continues to be a ubiquitous part of families' lives and may play a role in and/or reflect the parent-child relationship.

\section{Conflict of Interest}

The authors declare that the research was conducted in the absence of any commercial or financial relationships that could be construed as a potential conflict of interest.

\section{Acknowledgments}

Research reported in this publication was supported in part by awards from the National Endowment for the Arts (1844332-38-C-18 and 1863278-38), National Center for Complementary and Integrative Health (NCCIH) of the National Institutes of Health, and the NCATS/NIH (UL1 TR000445). The content is solely the responsibility of the authors and does not necessarily represent the official views of the National Institutes of Health $(\mathrm{NIH})$ or the National Endowment for the Arts (NEA). The NIH and NEA do not guarantee the accuracy or completeness of the information included in this report and are not responsible for any consequence of its use. This work was additionally supported by the VUMC Faculty Research Scholars Program and the VUMC Department of Otolaryngology.

\section{References}

Altig, D., Baker, S., Barrero, J. M., Bloom, N., Bunn, P., Chen, S. et al. (2020). Economic uncertainty before and during the COVID-19 pandemic. Journal of Public Economics, 191, 104274. 
Atkinson, L., Paglia, A., Coolbear, J., Niccols, A., Parker, K. C., \& Guger, S. (2000). Attachment security: A meta-analysis of maternal mental health correlates. Clinical Psychology Review, 20(8), 1019-1040.

Bartik, A. W., Cullen, Z. B., Glaeser, E. L., Luca, M., \& Stanton, C. T. (2020). What jobs are being done at home during the COVID-19 crisis? Evidence from firm-level surveys. National Bureau of Economic Research.

Blackburn, C. (2017). Young children's musical activities in the home. Education 3-13, 45(6), 674-688. http://dx.doi.org/10.1080/03004279.2017.1342320

Borkowski, J. G., Ramey, S. L., \& Bristol-Power, M. (Eds.). (2001). Parenting and the child's world: Influences on academic, intellectual, and social-emotional development. Psychology Press.

Bulfone, T., Quattrin, R., Zanotti, R., Regattin, L., \& Brusaferro, S. (2009). Effectiveness of music therapy for anxiety reduction in women with breast cancer in chemotherapy treatment. Holistic nursing practice, 23(4), 238-242.

Calarco, J. M., Anderson, E., Meanwell, E. V., \& Knopf, A. (2020). "Let's not pretend it's fun": How COVID-19-related school and childcare closures are damaging mothers' well-being. https://doi.org/10.31235/osf.io/jyvk4

Cirelli, L. K., Einarson, K. M., \& Trainor, L. J. (2014). Interpersonal synchrony increases prosocial behavior in infants. Developmental science, 17(6), 1003-1011.

Cirelli, L. K., Trehub, S. E., \& Trainor, L. J. (2018). Rhythm and melody as social signals for infants. Annals of the New York Academy of Sciences, 1423(1), 66-72.

Cirelli, L. K., Jurewicz, Z. B., \& Trehub, S. E. (2020). Effects of maternal singing style on mother-infant arousal and behavior. Journal of Cognitive Neuroscience, 32(7), 1213 1220.

Condon, J. T., \& Corkindale, C. J. (1998). The assessment of parent-to-infant attachment: Development of a self-report questionnaire instrument. Journal of Reproductive and Infant Psychology, 16(1), 57-76.

Craig, L., \& Churchill, B. (2020). Dual-earner parent couples' work and care during COVID-19. Gender, Work \& Organization.

Croom, A. M. (2015). Music practice and participation for psychological well-being: A review of how music influences positive emotion, engagement, relationships, meaning, and accomplishment. Musicae Scientiae, 19(1), 44-64.

Custodero, L. A., \& Johnson-Green, E. A. (2008). Caregiving in counterpoint: Reciprocal influences in the musical parenting of younger and older infants. Early Child Development and Care, 178(1), 15-39.

Custodero, L. A., Rebello Britto, P., \& Brooks-Gunn, J. (2003). Musical lives: A collective portrait of American parents and their young children. Journal of Applied Developmental Psychology, 24(5), 553-572. https://doi.org/10.1016/j.appdev.2003.08.005

Czeisler, M.É., Lane, R.I., Petrosky E., Wiley, J.F., Christensen, A., Njai, R. et al. (2020). Mental Health, Substance Use, and Suicidal Ideation During the COVID-19 Pandemic United States, June 24-30, 2020. Morbidity and Mortality Weekly Report. 69, 10491057. http://dx.doi.org/10.15585/mmwr.mm6932a1

de Cock, Evi S.A., Henrichs, J., Vreeswijk, C. M. J. M., Maas, A. J., Rijk, C. H. A. M., \& van Bakel, Hedwig J.A. (2016). Continuous feelings of love? The parental bond from pregnancy to toddlerhood. Journal of Family Psychology, 30(1), 125-134. 
de Vries, P. (2009). Music at home with the under fives: What is happening? Early Child Development and Care, 179(4), 395-405. https://doi.org/10.1080/03004430802691914

Del Boca, D., Oggero, N., Profeta, P., \& Rossi, M. (2020). Women's Work, Housework and Childcare, before and during COVID-19. IZA Discussion Paper No. 13409

Dey, M., Frazis, H., Loewenstein, M., \& Sun, H. (2020). Ability to work from home: Evidence from two surveys and implications for the labor market in the COVID-19 pandemic. Monthly Labor Review, 1-19.

Dunbar, R. I. M. (2012). Bridging the bonding gap: the transition from primates to humans. Philos. Trans. R. Soc. Lond. B Biol. Sci. 367, 1837-1846.

Erkkilä, J., Punkanen, M., Fachner, J., Ala-Ruona, E., Pöntiö, I., Tervaniemi, M., ... \& Gold, C. (2011). Individual music therapy for depression: randomised controlled trial. The British journal of psychiatry, 199(2), 132-139.

Fancourt, D., \& Perkins, R. (2017). Associations between singing to babies and symptoms of postnatal depression, wellbeing, self-esteem and mother-infant bond. Public Health, 145, 149-152.

Fancourt, D., \& Perkins, R. (2018a). Effect of singing interventions on symptoms of postnatal depression: three-arm randomised controlled trial. The British Journal of Psychiatry, 212(2), 119-121.

Fancourt, D., \& Perkins, R. (2018b). The effects of mother-infant singing on emotional closeness, affect, anxiety, and stress hormones. Music \& Science, 1 . https://doi.org/10.1177/2059204317745746

Forman-Hoffman, V. L., Muhuri, P. K., Novak, S. P., Pemberton, M. R., Ault, K. L., \& Mannix, D. (2014). Psychological distress and mortality among adults in the US household population. CBHSQ data review.

Freeman, W. J. III. (2000). A neurobiological role of music in social bonding. In N. Wallin, B. Merkur, and S. Brown (Eds.), The Origins of Music (pp. 411-424). MIT Press.

Gassman-Pines, A., Ananat, E. O., \& Fitz-Henley, J. (2020). COVID-19 and parent-child psychological well-being. Pediatrics, 146(4).

Goodman, S. J., \& Glenwick, D. S. (2012). Correlates of attachment perceptions in parents of children with Autism Spectrum Disorders. Journal of Autism and Developmental Disorders, 42(10), 2056-2066. https://doi.org/10.1007/s10803-012-1453-8

Hansen, K., Jones, E., Joshi, H., \& Budge, D. (2010). Millennium Cohort Study Fourth Survey: A user's guide to initial findings. London: Centre for Longitudinal Studies, University of London.

Hanser, S. B., \& Thompson, L. W. (1994). Effects of a music therapy strategy on depressed older adults. Journal of gerontology, 49(6), 265-269.

Hargreaves, D. J., \& North, A. C. (1999). The functions of music in everyday life: Redefining the social in music psychology. Psychology of music, 27(1), 71-83.

Harris, P. A., Taylor, R., Thielke, R., Payne, J., Gonzalez, N., \& Conde, J. G. (2009). Research electronic data capture (REDCap) - a metadata-driven methodology and workflow process for providing translational research informatics support. Journal of biomedical informatics, 42(2), 377-381.

Ilari, B. (2005). On musical parenting of young children: Musical beliefs and behaviors of mothers and infants. Early Child Development and Care, 175(7-8), 647-660. https://doi.org/10.1080/0300443042000302573 
Johnson, K. (2013). Maternal-infant bonding: A review of literature. International Journal of Childbirth Education, 28(3), 17-22.

Kessler, R. C., Andrews, G., Colpe, L. J., Hiripi, E., Mroczek, D. K., Normand, S. L., Walters, E. E., \& Zaslavsky, A. M. (2002). Short screening scales to monitor population prevalences and trends in non-specific psychological distress. Psychological Medicine, 32(6), 959976.

Kirschner, S., \& Tomasello, M. (2010). Joint music making promotes prosocial behavior in 4year-old children. Evolution and Human Behavior, 31(5), 354-364.

Kohlhoff, J., \& Barnett, B. (2013). Parenting self-efficacy: Links with maternal depression, infant behaviour and adult attachment. Early human development, 89(4), 249-256.

Kreutz, G., Murcia, C. Q., \& Bongard, S. (2012). Psychoneuroendocrine research on music and health: an overview. Music, health, and wellbeing, 457-476

Lee, S. J., Ward, K. P., Chang, O. D., \& Downing, K. M. (2020). Parenting activities and the transition to home-based education during the COVID-19 pandemic. Children and Youth Services Review, 105585.

Lense, M. D., Beck, S., Liu, C., Pfeiffer, R., Diaz, N., Lynch, M., ... \& Fisher, M. H. (2020). Parents, peers, and musical play: Integrated parent-child music class program supports community participation and well-being for families of children with and without autism spectrum disorder. Frontiers in Psychology, 11, 2775.

Lense, M. D., \& Jones, W. R. (2016). Beat-based entrainment during infant-directed singing supports social engagement. In Proceedings of the 14th international conference on music perception \& cognition (icmpc14). San Francisco, CA, July 5-9.

Linnemann, A., Ditzen, B., Strahler, J., Doerr, J. M., \& Nater, U. M. (2015). Music listening as a means of stress reduction in daily life. Psychoneuroendocrinology, 60, 82-90.

Mehr, S. A., Song, L. A., \& Spelke, E. S. (2016). For 5-month-old infants, melodies are social. Psychological Science, 27(4), 486-501.

Mendoza, J. K., \& Fausey, C. M. (2019). Everyday music in infancy. PsyArXiv. https://doi.org/10.31234/osf.io/sqatb

Moore, K. S. (2013). A systematic review on the neural effects of music on emotion regulation: implications for music therapy practice. Journal of music therapy, 50(3), 198-242.

Nicholson, J. M., Berthelsen, D., Abad, V., Williams, K., \& Bradley, J. (2008). Impact of music therapy to promote positive parenting and child development. Journal of Health Psychology, 13(2), 226-238.

Patrick, S. W., Henkhaus, L. E., Zickafoose, J. S., Lovell, K., Halvorson, A., Loch, S., ... \& Davis, M. M. (2020). Well-being of parents and children during the COVID-19 pandemic: a national survey. Pediatrics, 146(4).

Perkins, R., Yorke, S., \& Fancourt, D. (2018). How group singing facilitates recovery from the symptoms of postnatal depression: A comparative qualitative study. BMC Psychology, 6(1), 41. https://doi.org/10.1186/s40359-018-0253-0

Persico, G., Antolini, L., Vergani, P., Costantini, W., Nardi, M. T., \& Bellotti, L. (2017). Maternal singing of lullabies during pregnancy and after birth: Effects on mother-infant bonding and on newborns' behaviour. Concurrent Cohort Study. Women and Birth, 30(4), e214-e220.

Politimou N., Stewart L., Müllensiefen D., Franco F. (2018). Music@Home: A novel instrument to assess the home musical environment in the early years. PLoS ONE, 13(4). https://doi.org/10.1371/journal.pone.0193819 
Russell, B. S., Hutchison, M., Tambling, R., Tomkunas, A. J., \& Horton, A. L. (2020). Initial Challenges of Caregiving During COVID-19: Caregiver Burden, Mental Health, and the Parent-Child Relationship. Child Psychiatry \& Human Development, 51(5), 671-682. https://doi.org/10.1007/s10578-020-01037-x

Savage, P., Loui, P., Tarr, B., Schachner, A., Glowacki, L., Mithen, S., \& Fitch, W. (2020). Music as a coevolved system for social bonding. Behavioral and Brain Sciences, 1-36. doi:10.1017/S0140525X20000333

Steinberg, S., Shivers, C.M., Liu, T., Cirelli, L.K., \& Lense, M.D. (2020). Musical engagement and parent-child attachment in families of young children with and without developmental disabilities. https://doi.org/10.31234/osf.io/xveqy

Tarr, B., Launay, J., \& Dunbar, R. I. (2014). Music and social bonding:"self-other" merging and neurohormonal mechanisms. Frontiers in psychology, 5, 1096.

Thayer, R. E., Newman, J. R., McClain, T. M. (1994). Self-regulation of mood: Strategies for changing a bad mood, raising energy, and reducing tension. Journal of Personality and Social Psychology, 67, 910-925.

Thoma, M. V., Ryf, S., Mohiyeddini, C., Ehlert, U., \& Nater, U. M. (2012). Emotion regulation through listening to music in everyday situations. Cognition \& emotion, 26(3), 550-560.

Tomitaka, S., Kawasaki, Y., Ide, K., Akutagawa, M., Ono, Y., \& Furukawa, T. A. (2019). Distribution of psychological distress is stable in recent decades and follows an exponential pattern in the US population. Scientific reports, 9(1), 1-10.

Trehub, S. E., Plantinga, J., \& Russo, F. A. (2016). Maternal vocal interactions with infants: Reciprocal visual influences. Social Development, 25(3), 665-683.

Twenge, J., \& Joiner, T. (2020). Mental distress among US adults during the COVID-19 pandemic. https://doi.org/10.31234/osf.io/wc8ud

U.S. Chamber of Commerce Foundation (2020). Childcare: An essential industry for economic recovery. Childcare Providers and Covid-19, 3, 1-21.

Von Lob, G., Camic, P., \& Clift, S. (2010). The use of singing in a group as a response to adverse life events. International Journal of Mental Health Promotion, 12(3), 45-53.

Yehuda, N. (2011). Music and stress. Journal of Adult Development, 18(2), 85-94. https://doi.org/10.1007/s10804-010-9117-4

Zubrick, S. R., Smith, G. J., Nicholson, J., Sanson, A., \& Jackiewicz, T. A. (2008). Parenting and families in Australia. FaHCSIA Social Policy Research Paper. 